\title{
ENTRE BENJAMIN Y SCHMITT: EL ROMPECABEZAS DE JOSÉ ARICÓ PARA PENSAR AMÉRICA LATINA
}

\author{
Martín Cortés \\ Universidad de Buenos Aires \\ Université Paris VIII
}

\begin{abstract}
Resumen: El presente trabajo se inscribe en un trabajo de tesis doctoral en torno a la obra del pensador argentino José Aricó (1931-1991), centrado en sus contribuciones a la producción de un marxismo latinoamericano. En este caso, presentamos una lectura de algunas de las diversas fuentes en que abrevaron los intentos de Aricó por enriquecer el pensamiento crítico latinoamericano. Mostrando una gran versatilidad para ello, nuestro autor acudió a diversas tradiciones teórico-políticas (que incluso pueden considerarse antagónicas entre sí) con el horizonte de "traducirlas" a las necesidades de pensar, desde una perspectiva marxista, la especificidad latinoamericana. Sus lecturas de Walter Benjamin, así como la edición, en 1984, de El concepto de lo político, de Carl Schmitt, constituyen dos momentos particularmente importantes de la trayectoria de Aricó, en lo que hace a sus formas de incidencia en los debates latinoamericanos. Nuestra hipótesis, en este punto, es que la originalidad y heterodoxia del marxismo latinoamericano de Aricó radica precisamente en su capacidad de conjugar diversas tradiciones con la perspectiva de desafiar y poner en diálogo al marxismo con diversos problemas políticos y corrientes culturales que lo exceden.
\end{abstract}

Palabras clave: José Aricó, Walter Benjamin, Carl Schmitt, Marxismo Latinoamericano

\begin{abstract}
This text takes part of a PhD thesis -in progress- about the work of argentinean thinker José Aricó (1931-1991), focusing on his contributions to the production of a latin american marxism. In this case, we present a reading of some of the various sources that Aricó took in his attempts to enrich the Latin American critical thought. Showing versatility for that goal, our author went to various theoretical and political traditions (which may even be considered antagonistic to each other) with the main goal of "translating" them to the needs of thinking, from a Marxist perspective, the latin american specificity. His readings of Walter Benjamin, and the publication, in 1984, of The Concept of the Political, of Carl Schmitt, are two particularly important stages on Aricó's path in regard to impact on latin american debates. Our hypothesis is that the originality and unorthodoxy of Aricó's Latin American marxism lies in his ability to cmbine different traditions, with the common perspective of challenge marxism with various and different political and cultural currents and schools of thought.
\end{abstract}

Keywords: José Aricó, Walter Benjamin, Carl Schmitt, Latin American Marxism

"No creo que alguna vez concluya el bendito libro sobre el socialismo latinoamericano, pero ya cumplió y tal vez siga cumpliendo una finalidad que no deja de alegrarme, pues da sentido a mi vida y un horizonte definido a mis preocupaciones intelectuales"

José Aricó 
En un breve texto que intenta trazar una semblanza de la experiencia de Pasado y Presente, José Aricó atribuye a la misma lo que podríamos pensar como su modo de entender el marxismo a lo largo de su prolífica trayectoria intelectual. Allí, el autor cordobés nos dice: "el marxismo que hizo suyo y defendió la revista Pasado y Presente era aquél que estaba en condiciones de soportar un productivo diálogo con el mundo y la cultura del presente"1 (cursivas nuestras). Parafraseando a Jean Paul Sartre, el marxismo como "horizonte insuperable de nuestra época" no está puesto en cuestión por Aricó, ni siquiera en sus épocas de reflexión política más pesimista (incluso es materia de debate si las posiciones teórico-políticas de Aricó y buena parte del grupo Pasado y Presente en los años ochenta suponen un abandono del marxismo o una interpretación específica -¿socialdemócrata?- del mismo). En todo caso, lo que aparece subrayado es la necesidad de poner ese marxismo en diálogo y confrontación permanente tanto con las más disímiles realidades políticas como, muy especialmente, con las diversas expresiones culturales de cada tiempo. Este era el núcleo central de lo que Aricó, en el mismo texto, llama "una visión laica del marxismo".

El presente trabajo tiene por objeto recorrer sucintamente algunos momentos de la trayectoria intelectual del autor cordobés, subrayando su versatilidad para tomar diferentes fuentes teóricas como vehículos de incorporación de problemáticas determinadas en los debates de época. Precisamente por tratarse de una figura que introdujo una gran cantidad de elementos en las discusiones latinoamericanos (principalmente, pero no solo, a través de los Cuadernos de Pasado y Presente), no aspiramos a agotar toda su obra. Inscribimos esta ponencia en una investigación de mayor alcance que aspira a dar cuenta de los aportes de José Aricó a la reflexión sobre el marxismo latinoamericano, bajo la hipótesis de que este autor llevó adelante una compleja y multifacética tarea de traducción, a la realidad latinoamericana, de textos, autores, debates y problemas tanto del marxismo clásico como de corrientes más subterráneas del pensamiento crítico, así como de fuentes ajenas al pensamiento de izquierdas. La noción de traducción -central en nuestra investigación- que manejamos remite a la idea de Gramsci acerca de la "traducibilidad de los lenguajes científicos y filosóficos" para pensar la compleja relación entre las diversas culturas nacionales y la civilización común que las contiene. La traducción supone un ejercicio complejo de articulación entre universal y singular, que no es nunca una aplicación mecánica de categorías abstractas a una realidad dada. Por el contrario, implica siempre la producción de algo nuevo. La metáfora lingüística es pertinente por cuanto toda traducción es por

\footnotetext{
${ }^{1}$ El texto, manuscrito, permanece inédito. Se titula "Pasado y Presente" y cuenta con apenas tres páginas. Se puede consultar en la Biblioteca José María Aricó, en la Universidad Nacional de Córdoba.
} 
definición imperfecta: no existe equivalencia entre palabras de distintos idiomas, sino que cada traducción puede ser pensada como un problema a plantear y no como una operación autoevidente ${ }^{2}$. De modo que las diferentes ediciones y empresas editoriales que Aricó animó son tomadas como fragmentos que componen un multiforme intento por someter la realidad latinoamericana a una reflexión crítica que se anime a abrevar en las más diversas y universales fuentes.

En esa dirección, en este caso indagaremos específicamente en dos autores que, en su diversidad, dan cuenta de una vocación de apertura de Aricó en su interpretación del marxismo. Así, Walter Benjamin y Carl Schmitt serán pensados, en su profunda diversidad, como piezas de un mismo rompecabezas, que también componen autores propios y ajenos de la tradición marxista como el propio Marx, Lenin, Mao, Gramsci, Althusser y Mariátegui, así como Lévi-Strauss, Lacan, Arendt, Weber y Kelsen, entre tantos otros.

\section{Aricó, Benjamin, los fragmentos y la historia de los oprimidos}

El recorrido de Walter Benjamin en la Argentina presenta una forma llamativamente sinuosa. Como lo muestra Luis García (2010), al menos desde la década del treinta es posible encontrar su nombre en programas de estudio de universidades argentinas. Sin embargo, a lo largo de las sucesivas décadas, su figura se resaltaría y se desdibujaría casi con la misma intensidad, y se vería sometido a permanentes querellas en torno de su interpretación que, a su modo, persisten en nuestros días. En cierto sentido, ese vaivén se emparenta con la propia biografía de Benjamin, dejado de lado en los círculos académicos europeos de entreguerras, oscilante y abarcativo en sus temáticas y recorridos personales, y ciertamente reflejo trágico de la época en que las catástrofes arrebataban al marxismo su optimismo histórico.

Fue ese perfil de autor marginado y al mismo tiempo imprescindible el que atrajo a Aricó. Aunque no encontramos en sus empresas editoriales publicaciones de Benjamin, sí podemos hallar relevantes referencias e invitaciones a leerlo, en particular a partir de los años ochenta, tiempo en que su obra se difundía de manera más generalizada. En un breve artículo publicado en La Ciudad Futura, Aricó hace un recorrido por la recepción y difusión de Benjamin en América Latina, entre cuyos momentos más importantes encontramos los ensayos reunidos por Héctor Murena y publicados por la editorial Sur, en 1967, que dieron verdadero inicio a la difusión en español del autor alemán. En ese artículo, Aricó señala que es incluso antes, a principios de los sesenta, inspirados por la lectura de la Historia social de la literatura y del arte de Arnold Hauser, que Pasado y Presente se propone publicar La obra de arte en la época de su reproductibilidad técnica, proyecto finalmente frustrado y que no sería retomado por el grupo (Aricó y Leiras, 1991).

\footnotetext{
${ }^{2}$ Un mayor desarrollo de nuestro proyecto general en torno de la obra de Aricó puede leerse en Cortés (2010).
} 
Aún cuando Aricó no edita a Benjamin, es sumamente interesante la minuciosidad con que narra las peripecias de su recepción latinoamericana. Casi como si fuera un lenguaje imprescindible para entender a un autor, y dando cuenta de su oficio de historiador intelectual, el cordobés invita a leer a Benjamin reconstruyendo la historia de sus lecturas. Algunos trazos de su obra convocados por Aricó pueden dar cuenta de cierta afinidad que éste construye, sobre la cual podemos ensayar el intento de leer a Aricó como él leyó a Benjamin.

Walter Benjamin resulta siempre un autor profundamente atrayente para los intentos por escapar de las grandes sentencias del marxismo sin salir -al menos totalmente- de su horizonte general. El "pesimismo revolucionario" de sus conocidas Tesis sobre el Concepto de Historia permite colocar bajo otra óptica el viejo problema del desarrollo histórico. La certeza benjaminiana de que uno de los grandes problemas del marxismo fue creer que era heredero del desarrollo capitalista, lo que equivalió a cierta empatía epistemológica con el positivismo y la figuración burguesa del tiempo lineal, homogéneo y vacío, da sustento a la necesaria consideración crítica que en América Latina debe hacerse acerca del problema del progreso histórico ${ }^{3}$.

El marxismo "a contracorriente" de Benjamin resulta, así, atrayente para la empresa intelectual de Aricó. En unas notas dispersas reunidas para una nueva edición que se haría de Marx y América Latina, éste señala la necesidad de recuperar al Benjamin que rechaza la dialéctica lineal que había caracterizado al marxismo, tanto en su versión socialdemócrata como en la soviética. Aricó llama a "Leer a Marx desde la perspectiva gramsciana-benjaminiana", combinación que se caracterizaría por "arrancar de la política", es decir, tomar como punto de partida la posibilidad de torcer la historia, escapando a toda forma del relato lineal. Algo de esa potencia crítica que Aricó detecta en Benjamin puede apreciarse en un breve texto que le dedica, con el cual inaugura un suplemento de La Ciudad futura dedicado al autor alemán. Lo llamativo de este texto es la identificación que parece darse entre su autor y la figura a la que alude. Si consideráramos la "obra" de Aricó no sólo en sus propios escritos, sino haciéndola extensible a las empresas intelectuales que animó (revistas, seminarios, ediciones), podríamos afirmar que las diferentes formas con que, a través de esos variopintos discursos, intervino en los debates de cada época, dan cuenta de un intelectual que no sólo

\footnotetext{
${ }^{3}$ En su onceava Tesis sobre el concepto de Historia, Benjamin (2007) afirma que "Nada ha corrompido tanto a los obreros alemanes como la opinión de que están nadando con la corriente". En este mismo sentido, encontramos en una serie de iniciativas de Aricó un intento por criticar los aspectos del pensamiento de Marx en que éste se emparenta con una filosofía de la historia admiradora del progreso moderno. Para ello acude a mostrar los diferentes momentos en que el propio Marx, sobre todo a partir de la década de 1860, cuestiona el concepto de progreso que podría subyacer a algunas de sus formulaciones teóricas, especialmente de El Capital. Cumplen esa función, entre otras ediciones, la publicación del intercambio epistolar con Vera Zassulich (Marx y Engels, 1980) y el movimiento populista ruso, la correspondencia con Nikolai Danielson, editor ruso de El Capital (Marx, Engels y Danielson, 1981) y, por supuesto, la redacción de Marx y América Latina (Aricó, 1982)

${ }^{4}$ Manuscrito disponible en la Biblioteca José María Aricó de la Universidad Nacional de Córdoba, bajo el nombre de "Proyecto de una nueva edición de „Marx y América Latina” (Caja 27, Folio 8).
} 
habla a través de sus obras, sino que lo hace también a través de los autores que edita (luego veremos cómo se plasma esta cuestión en la publicación de Carl Schmitt).

En el caso de Benjamin, Aricó manifiesta en una breve hoja la importancia de colocarse en un horizonte inspirado por el berlinés. En las primeras líneas del texto -y en su título-, aparece la caracterización que Kracauer hiciera de Benjamin, como un "aguafiestas", dado que "su pasión era desenmascarar, quitar esas construcciones ideológicas que en el estado de clase tornan inhumano el ser social" (Aricó, 1991:15). Hay dos aspectos de esa pasión que son subrayados por Aricó: por un lado, el compromiso por pensar la tarea intelectual como una actividad eminentemente política, pues "siempre vivió preocupado por insertar su obra en la práctica inmediata". En ese mismo sentido, Benjamin es la figura que expresa de modo más acabado al intelectual que atraviesa una época de crisis política: incorforme y reticente a la estabilidad y comodidad con que podría sustraerse de una realidad convulsionada. Lo cual nos lleva al segundo aspecto que marca Aricó: el arrojo para experimentar reflexiones que quizá la época no está preparada para atender. De allí el paralelo con "la figura conradiana del agente secreto" que penetra y se inmiscuye en las ideas dominantes para colocarlas en una perspectiva crítica y tornarlas inutilizables en su sentido original o dominante. Aricó formula una pregunta sobre Benjamin que bien podríamos pensar como un interrogante acerca de su propia figura: "Benjamin manifestaba simpatías por intelectuales tan dispares como el filonazi Carl Schmitt, el sionista Scholem o el marxista Brecht ¿Un marginal incomprendido e irreductible o un pensador valiente y astuto que se propuso llevar adelante un proyecto propio en las circunstancias adversas de un campo cultural lacerado por la intolerancia y el espíritu faccioso?". Así, el Aricó que escribe en plena "crisis del marxismo" y que reivindica al Benjamin marxista en la época en que se lo leía más emparentado a la crítica cultural cierra su texto expresando abiertamente la necesidad de identificarse con la figura del autor alemán: “Cuando la „caza al marxista' -ese nuevo fantasma que recorre el mundo amenaza ser un modo burdo y trivial de disfrazar la incapacidad del pensamiento crítico para volverse práctica transformadora, rescatar el carácter militante de la crítica benjaminiana sigue siendo un modo de cuestionar la aceptación indiscriminada de lo existente. Un modo, en fin, de ser también como él, un aguafiestas".

Comenzábamos este trabajo con un epígrafe en el cual nuestro autor alude al proyecto de construcción de historia de las izquierdas en América Latina como el "sentido" de su vida. Esa iniciativa, de la cual Marx y América Latina y La hipótesis de Justo serían sólo capítulos parciales ${ }^{5}$, bien puede ser pensada como un gran

\footnotetext{
${ }^{5}$ En una entrevista que le fue realizada en julio de 1986 por Waldo Ansaldi, Aricó afirma: "el planteo del problema de la incapacidad de Marx para abordar este continente inclasificable que es el nuestro, ya estaba hecha en un breve texto de no más de nueve páginas que debía servir de introducción a un libro sobre el socialismo en América Latina, que nunca fue terminado de escribir" (Aricó, 1999: 177). Asimismo, la introducción de Horacio Crespo a la reedición de Marx y América Latina recupera una serie de cartas de Aricó de los años setenta en que éste menciona, con cierta frustración, el "mamotreto" sobre el socialismo en América Latina que no lograba terminar (Crespo, 2010).
} 
proyecto benjaminiano que vendría a reivindicar una historia de los oprimidos en América Latina. Pero no se trata solamente de una inspiración o de una afinidad de contenidos. Encontramos, además, un modo de trabajo que los encuentra a ambos en el afán por la colección. Benjamin dedica numerosos textos a la figura del coleccionista, en algunos casos en estrecha relación con los libros y el conocimiento: "El coleccionismo es un fenómeno originario del estudio: el estudiante colecciona saber" (Benjamin, 2005: 228). Además, en las reflexiones benjaminianas, el coleccionista mira allí donde sólo parece haber residuos con la capacidad de cambiar el contexto de un elemento para crear una nueva constelación. Así puede ser pensado el sentido de las ediciones de Aricó, como fragmentos de saber que son recuperados y mudados a otro tiempo y lugar con el manifiesto propósito de intervenir en ese presente.

Tanto Benjamin como Aricó fueron coleccionistas. El Libro de los Pasajes es precisamente una colección de fragmentos que constituyen un montaje que emula la paradigmática experiencia moderna de la París decimonónica. Respecto de esa obra, Aricó la define como "equivalente, en el espacio multiforme de las superestructuras, al análisis de la estructura de la sociedad moderna llevada a acabo por Marx en El Capital" (Aricó, 1991:15). Ahora bien, hecho el paralelo entre Benjamin y Aricó, cabría preguntarse si el gran proyecto de llevar adelante un libro que reconstruya la historia del socialismo latinoamericano no es, en tanto unidad, una empresa imposible. En cuyo caso, no habría que lamentar que Aricó no haya concluido ese libro, sino llevar adelante una lectura de su obra como una colección de fragmentos que apuntan en esa dirección. De esta manera, sus escritos sobre Justo, Gramsci, Mariátegui, Marx, las advertencias y prólogos de los Cuadernos, así como las ediciones en que, como decíamos antes, habla a través de los otros, constituyen todos ellos fragmentos que componen, con una imposible pero a la vez imprescindible aspiración de unidad, un caleidoscopio de inquietudes en torno de las vicisitudes del marxismo en América Latina.

\section{"El tiempo de la política": Schmitt para las izquierdas}

En 1984, la editorial Folios publica, en México y en Buenos Aires, El concepto de lo político, del pensador alemán Carl Schmitt. Lo hace en el marco de la colección "El tiempo de la política", dirigida precisamente por José Aricó. No es casual el título de la colección ni la inscripción de Schmitt en la misma. Algunos textos publicados en ella fueron, entre otros, los Escritos Políticos de Max Weber, la compilación que llevaba por nombre Discutir el Estado (que reunía a los más importantes autores de la izquierda europea, a partir de una polémica iniciada por Louis Althusser) y el conocido Los usos de Gramsci, de Juan Carlos Portantiero. "El tiempo de la política" es, para Aricó, el tiempo de ampliar las lentes con que, desde el marxismo, se había leído la realidad latinoamericana. Se trata de la misma época en que los Cuadernos de Pasado y Presente publican una serie de textos dirigidos a poner en discusión la dimensión política del pensamiento marxista: tales son los casos, entre otros, de Teoría Marxista de la Política (AAVV, 1981), donde se compilan varios artículos extraídos de los debates italianos, principalmente en la Revista Critica Marxista, acerca de diversos temas que 
articulan marxismo y política. Un año después, aparece Lo Político y las transformaciones, de Giacomo Marramao (1982) -traducido por el propio Aricó-, que apunta a renovar la discusión sobre la "teoría política del marxismo". Allí, la "Advertencia", firmada por Pasado y Presente, pero en la que se barrunta el núcleo de las preocupaciones de Aricó, remarca la "búsqueda de las respuestas posibles al problema de la relación -aún percibida desde una perspectiva mecanicista- entre crítica de la economía política y crítica de la política". Por su parte, El concepto socialista de Nación, escrito por Leopoldo Mármora (1986) tiene por objeto revisar críticamente el derrotero del problema de la Nación y el Estado en Marx y el marxismo en general. Así, como anunciara Aricó en Marx y América Latina, el problema del Estado, de la Nación y de la política serán temas clave para la reflexión sobre las condiciones de producción de un marxismo latinoamericano. Para ello, fiel a su estilo, arrojará textos y traducciones al debate teórico y político en la Argentina y en toda la región.

Una vez más, este propósito es emprendido con la convicción de que la profunda reflexión autocrítica que el marxismo debe tener en los tiempos de su "crisis" tiene que confrontarse, necesariamente, con tradiciones de pensamiento que le excedan y que le permitan ponerse en diálogo con todos los aspectos de la cultura moderna. En ese marco puede leerse la incorporación de Schmitt al mutifacético rompecabezas de Aricó. En un libro sobre la trayectoria del pensamiento del autor alemán en la Argentina, Jorge Dotti, uno de sus más renombrados conocedores en América Latina, reconstruye la iniciativa de publicación emprendida por Aricó. Dotti insiste de diversos modos en inscribir dicha iniciativa en el esfuerzo de Aricó por "construir un polo de irradiación doctrinaria capaz de impulsar una visión democrática y progresista, mediante la profunda revisión y actualización de la tradición de izquierda" (Dotti, 2000a:697). La edición, además de componerse de El Concepto de lo Político, contiene una "Presentación" y una "Noticia Biográfica", ambas redactadas por Aricó, quien preparó, además, un apartado de bibliografía de y sobre Schmitt. Asimismo, aparecen una serie de textos más de Schmitt que discuten el problema de la neutralidad de lo político ("La época de las neutralizaciones y las despolitizaciones" y "Reseña de los diversos significados y funciones del concepto de neutralidad política interna del Estado", entre otros), cuestión crucial en las críticas de Aricó a ciertos modos de pensar desde las izquierdas. Volveremos sobre ello.

Es el propio editor y autor de la "Presentación", quien explica allí el sentido de la edición de Schmitt, así como su encadenamiento con un modo de intervención en el campo intelectual y político. Rápidamente, el autor cordobés afirma que el trabajo editorial es, ante todo, una empresa de "cultura crítica", lo que implica "instalarse siempre en el punto metódico de la "deconstrucción", en ese contradictorio terreno donde el carácter destructivo de un pensamiento que no se cierra sobre sí mismo es capaz de transformarse en constructor de nuevas maneras de abordar realidades cargadas de tensiones y de provocar a la vez tensiones productivas de un sentido nuevo" (Aricó, 1984: X). He aquí la continuidad de esta publicación con un modo de trabajo que ya llevaba al menos dos décadas. 
Dicho eso, ¿cuáles son los contenidos que hacen necesaria la publicación de Schmitt y por qué ello implicaría una empresa "crítica"? Como mencionábamos anteriormente, este proyecto puede inscribirse en la "agenda" de reflexión que Aricó propone para las izquierdas a partir de sus textos sobre el marxismo en América Latina. La necesidad de complejizar las reflexiones sobre la política permiten extender el "diálogo" entre el marxismo y otras expresiones de la cultura hasta el polémico Carl Schmitt.

Aricó inicia ese diálogo con una fuerte crítica al modo en que el marxismo se pensó a sí mismo como plena realización del proyecto de la llustración: "El marxismo, en definitiva, no indicaba la tentativa más radical de crítica de un mundo al que la crisis tornaba siempre más indecible, sino la consumación de las concepciones racionalistas que el cosmos burgués elevó a su máxima expresión" (Aricó, 1984: XI). El problema de la oposición entre racionalismo e irracionalismo, y la inscripción plena del marxismo en la primera de esas familias (propia de la perspectiva lukacsiana de El Asalto a la razón) sería un problema que debe ser atendido, en la medida en que las representaciones lineales modernas debían ser cuestionadas también desde el marxismo. De hecho, según Aricó, la propia crítica marxiana de la Economía Política fue despreciada en su dimensión más disruptiva respecto del saber moderno, y celebrada en aquello que la cristaliza como ciencia positiva. Por el contrario, nos dice Aricó en una llamativa expresión irracionalista, debe rescatarse "la demoníaca voluntad puesta de manifiesto [por Marx] en su deconstrucción de la Economía política como verdadera "ciencia" del poder de su época" (Aricó, 1984: XI, cursivas nuestras). Nótese que Aricó utilizó también, unas líneas antes, el término "deconstrucción" para dar cuenta de su proyecto editorial, lo cual lo emparenta con la lectura del marxismo como una filosofía crítica y negativa de la Modernidad, y no como su realización en tanto sistema filosófico ${ }^{6}$.

De modo que Schmitt resulta fundamentalmente un pensador "para la crisis". Crisis de la racionalidad moderna que es también, en los tempranos ochenta, "crisis del marxismo" en su modo de encadenarse con la tradición iluminista. La provocación (él mismo utiliza ese término) que introduce Aricó con la edición de Schmitt consiste en colocar la radicalidad de su crítica a la modernidad al servicio de la renovación del marxismo: "Como crítico "de derecha" de la sociedad burguesa Schmitt es un pensador reaccionario que considera a las conquistas iluministas como errores gravemente perniciosos para la humanidad. En tal sentido está en las antípodas de Marx. Pero aun con propósitos radicalmente opuestos a los suyos, Schmitt se sitúa en el pleno reconocimiento de lo que para nosotros caracteriza la contribución epocal que Marx produjo: la determinación esencialmente política de la economía" (Aricó, 1984: XI; cursivas nuestras). Hete aquí el "punto de encuentro" entre Marx y Schmitt. Remarcamos dos trazos de la cita que dan cuenta de la disputa teórica que Aricó emprende. Tanto el "para nosotros" como la última afirmación del fragmento muestran la voluntad de incidir

\footnotetext{
${ }^{6}$ La cuestión del carácter no sistemático del proyecto marciano, leída "a contrapelo" de las interpretaciones ortodoxas que lo conciben como un sistema filosófico cerrado y autointeligible es desarrollada con mayor amplitud, en la misma época, por Oscar del Barco (1982).
} 
en el debate marxista, diferenciándose de las diversas formas que asumen las interpretaciones "economicistas" del marxismo.

Ahora bien, este "economicismo" no remite solamente a aquellas corrientes más fácilmente identificables bajo ese mote, esto es, a las diversas expresiones del marxismo "oficial". La interpelación hecha a través de Schmitt apunta a todas las tradiciones que, más o menos abiertamente, aceptan una escisión tajante entre política y economía que permita pensar el proceso económico como una forma de lo técnico, y no como un espacio donde lo político es constitutivo, aún cuando aparezca neutralizado por el discurso de la ciencia económica. Este punto que, según Aricó, reúne a Schmitt y a Marx, no siempre ha sido tenido en cuenta por las izquierdas.

Así, Aricó propone un diálogo directo entre Schmitt y Marx, en el marco del cual el primero sirve para cuestionar algunas premisas del pensamiento marxiano, pero sobre todo para impugnar las interpretaciones que han hecho del marxismo un pensamiento centrado en lo "económico". No es tan relevante si, como afirma Schmitt, Marx hace empatía con el relato ilustrado de la pujante burguesía, como dar cuenta críticamente de las lecturas que han insistido en situar y retener al marxismo en el terreno económico. De ese modo, la crítica de la política sólo podía ser pensada como "emanación directa de la crítica de la economía política" (Aricó, 1984: XII). Y, aunque la escritura de Marx esté plagada de tensiones en esa materia, lo cierto es que Schmitt ataca con agudeza el fundamento esencialista del marxismo que, en tal sentido, lo transformaba en una filosofía de la historia que reposaba sobre la esfera económica como generadora de validez para todo el sistema ${ }^{7}$.

Así se constituye el objeto con el que la edición de Schmitt confronta. Con el propósito de extender el campo de la política como problema a discutirse, Aricó acude al autor alemán, destacando que su desarrollo sobre lo político se construye eludiendo todo intento de inscribirlo en una filosofía de la historia o en una forma de justificación del orden. Los destacados de Aricó para defender la pertinencia de su empresa se sustentan, fundamentalmente, en la crítica del Estado liberal que emprende Schmitt, a partir de la cual desplaza toda concepción normativa del orden, reduciéndolo a los modos en que se expresa la autoridad "del más fuerte". Con la guerra como trasfondo y como amenaza existencial (al estilo hobbesiano), la política queda descentrada respecto del Estado: éste ya no es el locus de lo político, ya que sociedad y Estado se compenetran y confunden. De ese modo, es la distinción amigo-enemigo la que opera como productora del orden, a partir de lo cual proliferan diversos sujetos políticos que evidencian la crisis de la autoridad legal del Estado como monopolio de lo político. La riqueza del pensamiento de Schmitt es, así, más fuerte que las reticencias que su trayectoria política puede generar:

\footnotetext{
${ }^{7}$ En este texto, Aricó hace algunas breves aclaraciones que intentan despegar al propio Marx del marxismo como filosofía de la historia, aún señalando sus tensiones al respecto. Desde algunos años antes de la edición de Schmitt, Aricó se encontraba rastreando un marxismo crítico de la idea de progreso (ver supra, nota 3).
} 
Sería un error, sin embargo, considerar su adhesión al nazismo como una consecuencia necesaria de su teoría, porque procediendo de tal mdoo liquidaríamos con su nazismo la novedad radical de su pensamiento y de su tentativa de colocar la reflexión a la altura del tiempo "fuerte" de lo política y de la crisis en la forma de estado (Aricó, 1984: XVIII)

El gran aporte de Schmitt es, entonces, el de abrir la posibilidad de pensar la complejidad de lo político. Aricó cita al ya mencionado Marramao, quien lee a Schmitt desde la izquierda europea, donde encontramos que el núcleo de interés del pensamiento de Schmitt, más allá de sus aporías y matices, está en iluminar el problema de la "asincronía entre ratio económico-productiva y ordenamiento político-institucional” (Marramao, citado en Aricó, 1984: XVIII).

A propósito de esta "asincronía", algunos años antes de la edición de Schmitt, Aricó publicaba un llamativo texto en la revista Controversia, que sirviera precisamente de espacio de reflexión para un importante núcleo de la intelectualidad argentina exiliada en México. Allí, discutiendo la cuestión de la "transición", Aricó advierte sobre la necesidad de complejizar los modos en que se pensó el vínculo entre sus aspectos económicos y políticos. En general, afirma nuestro autor, se tendió a reificar un concepto "productivista" de socialismo, con el cual se confió la transición más a la cuestión de la propiedad de los medios de producción que a la democratización de la sociedad. En una crítica llamativamente similar a la que recupera de Schmitt, Aricó afirma: "En sociedades complejas como lo son cada vez más las modernas, el socialismo no pareciera poder abrirse paso con base en una confianza iluminista en la capacidad de la razón programadora, sino al revés, cuestionándola en todo lo que tiene de recuperación neocapitalista" (Aricó, 1980: 15). De aquí se deduce la necesidad de problematizar la idea de democracia real no ya como "consecuencia" de la transición (o, su reverso, la democracia formal como mero "disfraz" burgués), sino como un complejo proceso inmanente al problema de la transición: "Tratando de no abandonar el campo de la democracia, los socialdemócratas olvidaron el socialismo. Aferrados al mito del socialismo como superador de la democracia, los comunistas acabaron instalando una autocracia. Lo que quedó fue cualquier cosa, pero nunca socialismo" (Ibídem: 15). Así el problema del vínculo entre democracia política y socialización económica es precisamente eso: un problema, una tensión que debe ser explorada, y no una autoevidencia expresiva de una razón universal que opera subterráneamente.

A partir de este problema se construye la operación de traducción llevada adelante por Aricó. La actualidad de Schmitt es la acuciante necesidad de reflexionar acerca de la emancipación cuando ya no hay garantías para ella, en términos de una filosofía de la historia que la tenga por coronación, ni un sujeto que la porte esencialmente: "La diversidad de lo real muestra hoy, para quien se empeña en leer en el presente los signos del mundo del mañana, la materialidad de un sujeto que se presenta como irreductible al sueño utópico de una sede privilegiada -sea el estado, el partido o la iglesia- desde el cual se dicte la ley del mundo" (Aricó, 1984: XX). 
Antes de las conclusiones, quisiéramos hacer una breve mención a la recepción que tuvo la edición de El Concepto de lo político, ya que ella da cuenta tanto del arrojo que envolvía la propuesta de Aricó como de su, dicho de manera terminante, imposibilidad. El presentador no esquiva, en el estudio introductorio del libro en cuestión, la necesidad de atender a las reservas que produciría la publicación de Schmitt, dada su conocida afinidad con el nazismo. Sin embargo, elige confrontar con dichas reservas, y postular la necesidad de que las izquierdas accedan a la riqueza del pensamiento schmitteano. En una fórmula similar a la que encontramos en el breve texto acerca de la experiencia de Pasado $y$ Presente, Aricó comienza a concluir la "Presentación" afirmando que

Para estar a la altura de las demandas de nuestro mundo histórico, para aferrar de manera productiva los nudos centrales del debate en torno al significado actual de la crítica del estado y de lo político, es imprescindible que el pensamiento de la transformación sepa medirse con la gran cultura burguesa que a través de Nietzsche y Weber, pero también de Schmitt, sometió a una crítica decisiva e irreversible la pretensión del estado moderno de fundar instancias hegemónicas totalizantes. Una crítica de la forma burguesa de lo político resultaría parcial, mutiladora, y finalmente estéril, si dejara de lado por prejuicios políticos o morales, que en el caso de ser válidos reclaman otras sedes y formas de debate, el análisis de una obra que, como la de Carl Schmitt, ha fijado una impronta insoslayable en la vida espiritual del siglo XX (Aricó, 1984: XX)

Una vez explicada la necesidad de leer a Schmitt en tanto expresión de la cultura de nuestro tiempo, el texto finaliza con la invitación, casi imperativa, a que las izquierdas se enfrenten con este legado y lo procesen críticamente:

Para que deje de ser patrimonio exclusivo de la derecha, o de la academia, para que entre en el debate de izquierda de manera plena, y para que éste pueda medirse con los grandes enemigos de sus propuestas, y no con sus mediocres escribas, incluimos a Carl Schmitt en nuestra colección. ¡Ojalá sea leído con la comprensión y el espíritu crítico que el excepcional valor de su obra se merece! (Ibídem: XXI)

Ni comprensión, ni espíritu crítico: como lo muestra Jorge Dotti en el citado artículo, basándose en reseñas del libro en cuestión y mesas de debate alrededor del pensamiento del autor alemán, la recepción de la provocación ariqueana no fue buena, apoyada antes en el rechazo a la figura de Schmitt que en una lectura profunda de sus propuestas teóricas. Paradójicamente, la reticencia hacia la iniciativa de Aricó no salió desde el objeto y la preocupación que aparecen como centrales en su "Presentación". No es el marxismo clásico, ortodoxo o economicista el que rechaza el intento por complejizar el pensamiento político marxista echando mano de los aportes de Schmitt. Por el contrario, el problema es el clima democrático-liberal que sobrevuela el campo intelectual en el marco de la problemática de la transición democrática:

Aricó, entonces, puede no haber sopesado adecuadamente cuán extemporánea era su presentación de escritos cuyo nervio es una crítica al liberalismo. O quizá los publicara precisamente por eso. Cualquiera fuese su propósito, y pese a sus 
aclaraciones y sugerencias, las intenciones de Aricó exigen un tipo de lector que en el momento político y cultural del 83 y años inmediatamente siguientes no es fácil de fomentar (Dotti, 2000b: 705; cursivas en el original)

Curiosamente, la propuesta de Aricó no tiene eco porque, de algún modo, carece de auditorio posible. La mayor parte de la intelectualidad ya no manifestaba tanta preocupación por complejizar las reflexiones marxistas sobre la política, cuanto por recuperar los valores democráticos de la tradición liberal que permitieran expulsar los fantasmas autoritarios heredados de la reciente dictadura militar y de las convulsionadas décadas previas, para cuyo propósito Schmitt era a todas luces incompatible ${ }^{8}$.

Aunque no tenga la merecida recepción, la propuesta de Aricó sí puede leerse hoy como un trazo más que configura la iniciativa general de "renovación del marxismo" que caracterizó su obra. En todo caso, para continuar con ese proyecto, se trataría de ser "ariqueanos" con el propio Aricó, traduciendo esas reflexiones pasadas a los desafíos del presente.

\section{Conclusiones: el marxismo latinoamericano será heterodoxo, o no será nada}

Solamente retornando a aquella condición "laica" del marxismo de Aricó, es posible articular iniciativas tan disímiles como las aquí consignadas, en un mismo horizonte de producción teórico-política. En esa dirección colocamos la idea de traducción como ordenadora de las iniciativas de Aricó relativas a América Latina, que permiten ubicarlo en el espacio teórico que intenta evadir dos problemas que, según Michael Lowy (2007), aquejaron al marxismo latinoamericano a lo largo de su historia: el eurocentrismo, consistente en la idea de que en la región podían aplicarse acríticamente las categorías desarrolladas por los autores marxistas

\footnotetext{
${ }^{8}$ Quizá, a modo de hipótesis, este vacío en que cae la invocación ariqueana sí podría vincularse con la mencionada cuestión del "societalismo" marxiano al que Aricó alude críticamente en su Marx y América Latina. Es posible encontrar algunos autores que emparentan el "antiestatismo" de Marx, en particular en su etapa de juventud, con la tradición liberal, con la cual compartiría el discurso de rechazo radical al Estado, asociado por principio con el autoritarismo (Rosanvallon, 2006; Lechner, 1981; Landi, 1981). Algo similar podría pensarse del clima intelectual argentino de comienzos de los ochenta, en el cual la reflexión acerca del cambio social comienza a fundarse más en las capacidades autónomas de la sociedad civil que en las herramientas políticas para llevarlo adelante. La revisitada relación entre socialismo y democracia aparece, así, como la necesidad de la democratización gradual de la sociedad en su conjunto, antes que como la dirección política de un proceso de transformación radical. No deja de resultar paradójico, en este punto, que el propio Aricó sea uno de los principales pensadores que dedican sus reflexiones, en los ochenta, a ese tipo de composiciones conceptuales. Sin embargo, también podríamos plantear que la tensión entre una compleja reflexión sobre la política y un pensamiento acerca de la democratización social es precisamente aquello que faltó en una década reticente a pensar la dimensión política del cambio social. Quizá esa tensión en la que podríamos colocar a Aricó puede explicar parte de cierta "soledad" en sus empresas intelectuales y políticas de aquellos años: así como su introducción de Schmitt no registra mayores ecos, también sus derivas políticas van desde el entusiasmo con que lee -junto con otros intelectuales de la época, como Juan Carlos Portantiero y Emilio De Ípola- el proyecto alfonsinista en sus inicios hasta un manifiesto pesimismo acerca de las posibilidades de cambio, en todo plano, en la sociedad argentina hacia fines de los ochenta. Este recorrido puede verse en las entrevistas compiladas por Horacio Crespo (Aricó, 1999)
} 
"clásicos" y el exotismo, según el cual América Latina es absolutamente irreductible y singular, razón por la cual toda categoría pergeñada en otras latitudes pierde inmediatamente validez.

Como mencionáramos al inicio, este trabajo forma parte de un proyecto más amplio de investigación acerca del problema del marxismo latinoamericano en la obra de Aricó. Su recuperación de Benjamin y de Schmitt, en ese sentido, bien puede pensarse como una ampliación de las fuentes que pueden contribuir a enriquecer el pensamiento crítico latinoamericano, incorporándose al acervo de herramientas teóricas que posibilitarían la producción de una constelación de elementos acordes a las especificidades de la región.

Para permitirse estos ejercicios de traducción, Aricó parte de un marxismo por definición incompleto: "Es precisamente la "incompletitud" de la teoría marxiana la que forma parte de su estilo problemático y la torna más sugestiva. Un pensamiento no sistemático se presta mejor que una especulación concluida para ser retomado y continuado en el presente, como si fuese un discurso interrumpido. Pero la actualidad está en las preguntas que en ella se plantean"9. Hay aquí, nuevamente, fuertes reminiscencias benjaminianas. En tanto incompleta, la obra de Marx consiente la posibilidad de ser traducida, en los términos que planteábamos antes, que aparecen también en un sugestivo texto de Benjamin acerca, precisamente, de la figura del traductor. Allí, el autor de las Tesis sobre el concepto de Historia sostiene que "la traducción brota del original". La traducibilidad es, entonces, índice de que estamos frente a un clásico, que sobrevive porque sugiere permanentemente nuevos modos de ser leído. Al mismo tiempo, la traducción no sería posible si su aspiración suprema fuera la semejanza con el original. Antes que eso, la pretensión velada de la operación traductora es la de completar el "lenguaje puro", yuxtaponiendo las traducciones a la obra original en busca (una búsqueda por definición inacabada, inacabable y siempre fracasada, pero por ello productiva) de construir un lenguaje total, universal. Sin embargo, lo que demuestra la necesidad de traducir es que existe algo absolutamente singular en cada lengua, aquello que Benjamin califica como del orden de lo intraducible. De modo que el traductor no aspira a la fidelidad, sino que su función consiste en "encontrar en la lengua a la que se traduce una actitud que pueda despertar en dicha lengua un eco del original” (Benjamin, 2010).

Es, entonces, a partir de aquella imposibilidad de cierre, que es a la vez una riqueza, que se funda la imposibilidad de pensar el marxismo latinoamericano como la "aplicación" de categorías ya cerradas a la realidad de la región, y la necesidad de concebirlo como producción ${ }^{10}$ de conceptos que articulen la potencia crítica del marxismo con la especificidad de las realidades nacionales latinoamericanas. Así, la riqueza del legado de Aricó reposa en ofrecer una

\footnotetext{
${ }^{9}$ Esta frase corresponde al mismo manuscrito citado en la nota 4 (ver supra)

${ }^{10}$ El debate acerca de la aplicación, difusión o producción del marxismo en América Latina ocupó el centro de las reflexiones de Aricó, sobre todo en lo relativo a su recepción del pensamiento de Mariátegui. No nos ocupamos de ello en este trabajo por una cuestión de extensión, pero se trata sin dudas de un punto de partida fundamental para el estudio de la cuestión del marxismo latinoamericano en la obra del intelectual cordobés.
} 
interpretación herética del marxismo, despojada de todo vestigio teológico y que, al mismo tiempo, precisa ser constantemente interrogada y conmovida en sus más profundos fundamentos. Pues, como tan sugestivamente escribiera Jorge Luis Borges en 1932: "El concepto de texto definitivo no corresponde sino a la religión o al cansancio".

\section{Referencias}

AAVV (1981) Teoría Marxista de la Política. México, Cuadernos de Pasado y Presente.

Aricó, José (1980), “Ni cinismo ni utopía”, Controversia, Año II, № 9-10, México.

Aricó, José (1982), Marx y América Latina. México, Alianza.

Aricó, José (1984) "Presentación", en Schmitt, C.: El concepto de lo político. México, Folios.

Aricó, José (1991, febrero) "Walter Benjamin, el aguafiestas", en Revista La Ciudad Futura № 25/26, Buenos Aires.

Aricó, José (1999) Entrevistas 1974-1991. Córdoba, CEA-UNC.

Aricó, José y Leiras, Marcelo (1991, febrero) “Benjamin en español”, en Revista La Ciudad Futura $\mathrm{N}^{\circ} 25 / 26$, Buenos Aires.

Benjamin, Walter (2005) El Libro de los Pasajes. Madrid, Akal.

Benjamin, Walter (2007) Sobre el concepto de Historia. Tesis y fragmentos. Buenos Aires, Piedras de Papel.

Benjamin, Walter (2010) "La tarea del traductor", en Ensayos escogidos. Selección y traducción H. A. Murena. Buenos Aires, El Cuenco de Plata.

Borges, Jorge Luis (2007): “Las versiones homéricas", en Obras Completas, Tomo I. Buenos Aires, Emecé.

Cortés, Martín (2010, Primavera) "La traducción como búsqueda de un marxismo latinoamericano: la trayectoria intelectual de José Aricó", en Revista $A$ Contracorriente Vol. 7, No. 3, North Carolina State University [Online]. Disponible en: http://www.ncsu.edu/project/acontracorriente/spring_10/index.htm

Crespo, Horacio (2010) "El marxismo latinoamericano de Aricó. La búsqueda de la autonomía de lo político en la falla de Marx", en Aricó, J.: Marx y América Latina. Buenos Aires, Fondo de Cultura Económica.

Del Barco, Oscar (1982) "Introducción", en Marx, Karl Notas marginales al "Tratado de Economía Política" de Adolph Wagner. México, Cuadernos de Pasado y Presente.

Dotti, Jorge (2000a) "José Aricó y la cola de otro diablo", en Carl Schmitt en la Argentina. Rosario, Homo Sapiens.

Dotti, Jorge (2000b) "Respuestas acompañamientos y reacciones al planteo ariqueano", en Carl Schmitt en la Argentina. Rosario, Homo Sapiens. 
García, Luis (2010, marzo) "Constelación austral. Walter Benjamin en la Argentina”, en Revista Herramienta N 43, Buenos Aires.

Landi, Oscar (1981) "Sobre lenguajes, identidades y ciudadanías políticas", en Lechner, N. (comp.) Estado y política en América Latina. México, Siglo XXI.

Lechner, Norbert (1981) “Epílogo", en Lechner, N. (comp.) Estado y política en América Latina. México, Siglo XXI.

Löwy, Michael (2007) El Marxismo en América Latina. Santiago de Chile, LOM.

Mármora, Leopoldo (1986), El concepto socialista de Nación. México, Cuadernos de Pasado y Presente.

Marramao, Giacomo (1982), Lo político y las transformaciones. México, Cuadernos de Pasado y Presente.

Marx, Karl y Engels, Federico (1980), Escritos sobre Rusia: II El porvenir de la comuna rural rusa. México, Cuadernos de Pasado y Presente.

Marx, Karl; Danielson, Nikolai; Engels, Friedrich (1981) Correspondencia 18681895. México, Siglo XXI.

Rosanvallon, Pierre (2006) El capitalismo utópico. Buenos Aires, Nueva Visión. 